\title{
A novel virulence-associated protein, vapE, in Streptococcus suis serotype 2
}

\author{
XUE JI ${ }^{1,2^{*}}$, YANG SUN ${ }^{1,2^{*}}$, JUN LIU ${ }^{1,2}$, LINGWEI ZHU ${ }^{1,2}$, XUEJUN GUO ${ }^{1,2}$, \\ XULONG LANG ${ }^{1,2}$ and SHUZHANG FENG ${ }^{1,2}$
}

\begin{abstract}
${ }^{1}$ Molecular Bacteriology Department, Institute of Military Veterinary Science, Academy of Military Medical Sciences, Changchun, Jilin 130122; ${ }^{2}$ Key Laboratory of Jilin Province for Zoonosis Prevention and Control, Institute of Changchun Veterinary Science, Changchun, Jilin 130122, P.R. China
\end{abstract}

Received May 18, 2015; Accepted December 21, 2015

DOI: $10.3892 / \mathrm{mmr} .2016 .4818$

\begin{abstract}
Streptococcus suis serotype 2 (SS2) is an important pathogen that affects pigs. However, neither its virulence nor its pathogenesis of infection has yet to be fully elucidated. The present study identifies a novel virulence-associated protein $\mathrm{E}$ gene (vapE) of SS2. To investigate the importance of vapE in SS2 infection, a vapE knock-out mutant based on SS2 wild-type strain ZY458 was designated $458 \Delta$ vapE. 458 $\Delta$ vapE was generated through homologous recombination, using a combined plasmid with a vapE knock-out fragment and a pSET4s suicide vector. Additionally, the $458 \Delta$ vapE strain was transformed by a pAT18 shuttle plasmid containing the $v a p E$ gene. A functionally complemented strain for the vapE gene [termed 458 $\Delta$ vapE (pvapE)] was constructed. Animal experiments demonstrated that mice infected with ZY458 and $458 \Delta$ vapE (pvapE) exhibited severe clinical symptoms, including depression, apathy, fever, anorexia, emaciation, swollen eyes and neural disorders, and died within two days of infection. All mice infected with ZY458, and $85 \%$ of mice infected with $458 \Delta$ vapE (pvapE), died within 2 days of infection. In contrast, mice inoculated with $458 \Delta$ vapE exhibited only mild clinical symptoms in the first 2 days following infection, and recovered within a week. A bacterial colonization assay demonstrated the ability of the $458 \Delta$ vapE mutant SS2 strain to colonize the heart, liver, spleen, lung and kidney of infected mice. PCR analysis of the vapE gene revealed that functional vapE was detected in virulent strains, but not in avirulent and
\end{abstract}

Correspondence to: Professor Shuzhang Feng, Molecular Bacteriology Department, Institute of Military Veterinary Science, Academy of Military Medical Sciences, Building No. 1, 666 Liuying West Road, Jingyue Economic Development Zone, Changchun, Jilin 130122, P.R. China

E-mail: fengsz@hotmail.com

*Contributed equally

Key words: Streptococcus suis serotype 2, virulence-associated protein $\mathrm{E}$ gene, virulence factor carrier strains of S. suis SS2. These findings indicate that vapE is important for the pathogenesis of SS2.

\section{Introduction}

Streptococcus suis is a major pathogen affecting pigs. It is endemic in countries involved in pig husbandry; however, it may also lead to meningitis, endocarditis, septicemia, arthritis, polyserositis, pneumonia and sudden death in pigs. Occasionally, it may lead to serious zoonotic infections in humans (1). The large-scale outbreak of human S. suis (type) 2 infection, with the feature of streptococcal toxic shock syndrome, in the Jiangsu and Sichuan provinces of China (2) indicated that $S$. suis remains a challenge for public health.

Serotype 2 of S. suis (also termed SS2) is considered to be the most virulent of the 33 established serotypes of this pathogen. However, the primary factors contributing to its virulence have yet to be fully elucidated. Previous studies on virulence-associated factors of SS2 have focused primarily on the bacterial capsular polysaccharide, muramidase-released protein, extracellular protein factor and suilysin $(3,4)$. Over the last decade, a large number of putative virulence factors associated with SS2 have been investigated (4), including fibronectin- and fibrinogen-binding proteins (5), opacity factor of S. suis (6), peptidoglycan (7), glutamine synthetase (8), di-peptidyl peptidase IV (9), inosine 5-monophosphate dehydrogenase (10), trigger factor tig gene (11), virulence-associated gene A (12), Rgg transcription regulator (13), surface-associated subtilisin-like protease (14), catabolite control protein A (15) and superoxide dismutase A (16). Notably, an $89 \mathrm{~K}$ pathogenicity island (PAI) (17) and SalK/SalR (a two-component signal transduction system) (18) have been identified as requisites for the full virulence of ethnic Chinese isolates of highly pathogenic SS2. However, the importance of these proteins in the pathogenicity of SS2, and the pathogenesis of the infection triggered by $S$. suis, remain to be elucidated.

To identify genes contributing to the virulence of virulent strains, a previous study conducted suppression and subtractive hybridization using a ZY458 virulent SS2 strain and a $13 \mathrm{w}$ avirulent SS2 strain (19). A total of 42 genomic regions were identified as being present in the virulent strain, 
but were absent in the avirulent one (19). Protein E gene (termed vapE) is one of these 42 genes, although it is absent in the non-virulent SS2 strain 1330. The objective of the present study was to investigate the effects of the $\Delta 458 \mathrm{VapE}$ mutation on the virulence of SS2.

\section{Materials and methods}

Bacterial strains, plasmids and primers. Bacterial strains and plasmids used in the present study are listed in Table I. S. suis 2 strains were cultured in brain-heart infusion (BHI) broth (Difco; BD Biosciences, Franklin Lakes, NJ, USA) supplemented with $5 \%(\mathrm{v} / \mathrm{v})$ calf serum or BHI agar at $37^{\circ} \mathrm{C}$. Escherichia coli strain DH5 $\alpha$ was used for cloning purposes and was cultured in Luria broth (LB) or LB agar at $37^{\circ} \mathrm{C}(20)$. When recombinants were screened or cultured, plates or broth were supplemented with appropriate antibiotics at the following concentrations: i) Spectinomycin (Spc), $100 \mu \mathrm{g} / \mathrm{ml}$ for $S$. suis 2 with plasmid pSET4s and $50 \mu \mathrm{g} / \mathrm{ml}$ for DH5 $\alpha$ with plasmid pSET4; ii) ampicillin (Amp), $100 \mu \mathrm{g} / \mathrm{ml}$ for DH5 $\alpha$ with plasmid pMD18-T; iii) erythromycin (Ery), $8 \mu \mathrm{g} / \mathrm{ml}$ for S. suis 2 with plasmid pAT18 and $150 \mu \mathrm{g} / \mathrm{ml}$ for DH5 $\alpha$ with plasmid pAT18 (all antibiotics from Sigma-Aldrich, St. Louis, MO, USA). DNA extraction, cloning, transformation, and other molecular techniques used in the present study were implemented following protocols described previously (20). All primer synthesis and DNA sequencing were outsourced to Invitrogen (Thermo Fisher Scientific, Inc., Waltham, MA, USA).

Construction of the vapE mutant strain. The primers used in the current study are presented in Table II. The PCR was performed according to a standard protocol. Each reaction was conducted using a $50 \mu \mathrm{l}$ mixture containing $5 \mu \mathrm{l} 10 \mathrm{X}$ buffer, 50 pmol each primer, $2 \mathrm{mM}$ each deoxynucleoside triphosphate, 5 units Ex Taq polymerase (all obtained from Takara Biotechnology Co., Ltd., Dalian, China) and $5 \mu \mathrm{l}$ supernatant of denatured bacteria. The PCR was performed with a Techgene FTGENE2D thermocycler (Techne Ltd., Duxford, UK). In order to generate a vapE gene-deleted mutant, a primer set was designed with a 194 bp internal deletion in the vapE gene by overlap extension polymerase chain reaction (OE PCR), using denatured bacteria as the DNA template (20). Two pairs of primers (VapE-1/VapE-2 and VapE-3/VapE-4) were used to independently amplify the 674 and 743 bp fragments of vapE, including flanking sequences from genomic DNA of the wild-type SS2 strain, ZY458. 16S rDNA was used as the reference gene, the primers were as follows: Sense, 5'-AGA GTTTGATCCTGGCTCAG-3' and antisense, 5'-ACGGCT ACCTTGTTACGACTT-3'. Amplification was performed as follows: i) Initial denaturation at $94^{\circ} \mathrm{C}$ for $3 \mathrm{~min}$; ii) 30 cycles of $94^{\circ} \mathrm{C}$ for $30 \mathrm{sec}, 60^{\circ} \mathrm{C}$ for $30 \mathrm{sec}$ and $72^{\circ} \mathrm{C}$ for $50 \mathrm{sec}$; and iii) a final elongation step at $72^{\circ} \mathrm{C}$ for $10 \mathrm{~min}$. Primers VapE-2 and VapE-3 contained $15 \mathrm{nt}$ stretches complementary to each other; thus, the PCR fragments were fused by OE PCR using primers VapE-1 and VapE-4. The following PCR protocol was used: $3 \mathrm{~min}$ at $94^{\circ} \mathrm{C}$, followed by 30 cycles at $94^{\circ} \mathrm{C}$ for $30 \mathrm{sec}, 59^{\circ} \mathrm{C}$ for $30 \mathrm{sec}$ and $72^{\circ} \mathrm{C}$ for $1 \mathrm{~min} 40 \mathrm{sec}$, followed by $72^{\circ} \mathrm{C}$ for $10 \mathrm{~min}$. The resultant $1,417 \mathrm{bp}$ PCR product contained an internal in-frame deletion of $194 \mathrm{bp}$ in the vapE gene (from 1 to $194 \mathrm{nt}$ ). The PCR product was purified by DNA Gel Extraction kit (Takara Biotechnology Co., Ltd.) Band subsequently cloned into a pMD18-T vector using a pMD18-T Vector Cloning kit (Takara Biotechnology Co., Ltd.) to

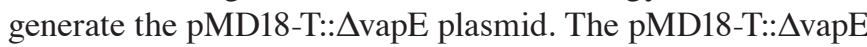
plasmid was digested with BamHI and EcoRI enzymes (Takara Biotechnology Co., Ltd., Dalian, China), and the DNA fragment containing the mutated vapE ( $\Delta$ vapE) was then cloned into a pSET4s thermosensitive suicide plasmid (21) to generate the pSET4s:: $\Delta$ vapE suicide plasmid. The resultant plasmid was confirmed by DNA sequencing and transfected into a ZY458 SS2 strain to screen for deletion mutants as described by Takamatsu et al (22). Subsequently, the SS2 strain ZY458 was electrotransfected with pSET4s:: $\triangle$ vapE using the ECM 399 electroporation system (BTX Harvard Apparatus, Inc., Holliston, MA, USA) at $2,000 \mathrm{~V}$, and cultured at $28^{\circ} \mathrm{C}$ in the presence of Spc to select the recombinant. The resultant ZY458 (pSET4s:: $\Delta$ vapE) cells were cultured in BHI broth with $\mathrm{Spc}$ at $28^{\circ} \mathrm{C}$ until the early logarithmic growth phase, and then were shifted to $37^{\circ} \mathrm{C}$ and incubated for an additional $10 \mathrm{~h}$. Subsequently, the cultures were diluted and spread onto BHI agar plates without antibiotic and incubated overnight at $37^{\circ} \mathrm{C}$. The cultures were screened for mutants that had lost the vectors and had exchanged their wild-type allele for a genetic segment containing the $\Delta$ vapE gene as a consequence of homologous recombination via a double cross-over. A resultant $458 \Delta$ vapE mutant strain was verified by PCR amplification with the primers VapE-5/VapE-R and further confirmed by DNA sequencing. The PCR cycle protocol, performed on Techgene FTGENE2D thermocycler, was as follows: i) Initial denaturation at $94^{\circ}$ for $3 \mathrm{~min}$; ii) 30 cycles of $94^{\circ} \mathrm{C}$ for $30 \mathrm{sec}$, $50^{\circ} \mathrm{C}$ for $30 \mathrm{sec}$ and $72^{\circ} \mathrm{C}$ for $40 \mathrm{sec}$; and iii) a final elongation step at $72^{\circ} \mathrm{C}$ for $10 \mathrm{~min}$.

Functional complemented vapE mutant strain. To generate a functionally complemented strain of $458 \Delta \mathrm{vapE}$, the structural gene of vapE with its promoter sequence (from $320 \mathrm{bp}$ upstream of the start codon to 439 bp downstream of the stop codon) was amplified using primers VapE-F and VapE-R. PCR was performed on a Techgene FTGENE2D thermocycler under the following conditions: i) Initiation and elongation, $3 \mathrm{~min}$ at $94^{\circ}$; ii) 30 cycles of denaturation for $30 \mathrm{sec}$ at $94^{\circ}$, annealing for $30 \mathrm{sec}$ at $50^{\circ} \mathrm{C}$; and iii) elongation for $2 \mathrm{~min}$ at $72^{\circ} \mathrm{C}$; and a final elongation step at $72^{\circ} \mathrm{C}$ for $10 \mathrm{~min}$. The PCR product (2,292 bp) was purified using the DNA Gel Extraction kit and subsequently cloned into pMD18-T to generate the plasmid, pMD18-T::vapE. The vapE fragment was then subcloned into shuttle vector pAT18. The resultant plasmid was verified by DNA sequencing, and subsequently used to electrotransfect the mutant strain 458 $\Delta$ vapE using the ECM 399 electroporation system, as described above (BTX Harvard Apparatus, Inc.), which was plated onto BHI agar supplemented with Ery to screen for the complemented strain, 458 $\Delta$ vapE (pvapE).

Bacterial growth curve. Wild-type strain S. suis 2 ZY458, mutant strain $458 \Delta \mathrm{vapE}$ and complemented strain $458 \Delta \mathrm{vapE}$ (pvapE) were separately inoculated into $100 \mathrm{ml}$ BHI broth and incubated at $37^{\circ} \mathrm{C}$. Samples of culture were monitored by spectrophotometry using a T6 UV spectrophotometer (Beijing Purkinje General Instrument Co., Ltd, Beijing, China). The 
Table I. Bacterial strains and plasmids used in the current study.

A, Plasmid

\begin{tabular}{lll}
\hline Name & \multicolumn{1}{c}{ Description } & \multicolumn{1}{c}{ Source } \\
\hline pMD18-T & A clone vector & Takara \\
pSET4s & Suicide vector, shuttle vector between E. coli and S. suis $(8,22)$ & Huazhong Agricultural University, China \\
pAT18 & Shuttle vector between E. coli and $S$. suis $(21,29)$ & Huazhong Agricultural University, China \\
\hline
\end{tabular}

$\mathrm{B}$, Bacterial strain

\begin{tabular}{|c|c|c|}
\hline Name & Description & Source \\
\hline DH5 $\alpha$ & Host cell for maintaining the recombinant plasmids & Takara \\
\hline ZY458 & $\begin{array}{l}\text { S. suis } 2 \text { wild-type strain, diseased pig } \\
\text { in Sichuan in } 2005, m^{+} p^{+} e p f^{+} s l y^{+}\end{array}$ & Our laboratory \\
\hline 1330 & S. suis 2, avirulence reference strain, mrp epf sly- & Canada (30) \\
\hline SP3 & S. suis 2 , Spanish strain, diseased pig, $m r p^{+} e p f^{+} s l y^{+}$ & Spain (31) \\
\hline SP6 & S. suis 2 , Spanish strain, diseased pig, $m r p^{+} e p f^{+} s l y^{+}$ & Spain (31) \\
\hline SP8 & S. suis 2, carrier strain, healthy pig, mrpe epf ${ }^{-} s l y^{-}$ & Spain (31) \\
\hline ZD89 & S. suis 2 , carrier strain, healthy pig, mrp-epf ${ }^{-}$sly $^{-}$ & Veterinary Institute of Harbin, China \\
\hline B22 & S. suis 2 , carrier strain, healthy pig, mrp-epf ${ }^{-}$sly- & Veterinary Institute of Harbin, China \\
\hline B3 & S. suis 2 , carrier strain, healthy pig, mrp-epf ${ }^{-}$sly- & Veterinary Institute of Harbin, China \\
\hline $458 \Delta$ vapE & vapE deletion mutant of $S$. suis 2 strain ZY458 & The present study \\
\hline $458 \Delta v a p E(\mathrm{pvapE})$ & $\begin{array}{l}\text { Complemented strain of } 458 \Delta v a p E, \\
\text { carrying the recombinant plasmid pAT18::vapE }\end{array}$ & The present study \\
\hline
\end{tabular}

Table II. Primers used for PCR amplification and identification.

\begin{tabular}{llcc}
\hline Primer & \multicolumn{1}{c}{ Sequence (5'-3') } & Restriction site & Position ${ }^{\text {a }(b p)}$ \\
\hline VapE-1 & GGATCCCACCAGCTTGCACATCGTC & BamHI & +850 to +868 \\
VapE-2 & GCCTGTTCCACCTTTGATAGTTGCCC & +194 to +220 \\
VapE-3 & AAAGGTGGAACAGGCCTTCTTTCTATGGTC & +195 to $+209 ;-1$ to -15 \\
VapE-4 & GAATTCGAAAACCCCGAAATTTATCAAGTG & EcoRI & -721 to -744 \\
VapE-5 & CCCTATCATTGATATAAATTCCCTC & +301 to +325 \\
VapE-U & TAGGTTTCCCCTTAAAGTGC & +1059 to +1078 \\
VapE-D & TACACCGCTAAACCTCTTTC & & -929 to -948 \\
VapE-F & GAATTCTCAGATTGTCATATTCACTAG & EcoRI & +1952 to +1972 \\
VapE-R & GGATCCATTGAGAAATACATGTTAG & BamHI & -302 to -320
\end{tabular}

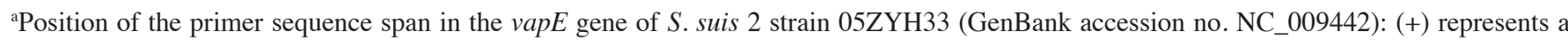
position upstream of the start codon of the $v a p E$ gene, whereas (-) represents a position downstream of the start codon of the $v a p E$ gene. The restriction sites are underlined.

absorbance was measured at $600 \mathrm{~nm}$ in a quartz cuvette (Beijing Purkinje General Instrument Co., Ltd.) at $1 \mathrm{~h}$ intervals. BHI broth minus the inoculation of bacteria served as a blank.

Experimental infection of mice. The present study was approved by the Review Board of the Academy of Military Medical Sciences (Changchun, China). All animal experiments were conducted in accordance with the accepted standards of the Animal Care and Use Committee of Academy of Military
Medical Sciences. The protocol was approved by the Animal Care and Use Committee of Academy of Military Medical Sciences and all efforts were made to minimize suffering. All experiments involving mice were conducted in accordance with the Council for International Organizations of Medical Sciences: International Guiding Principles for Biomedical Research Involving Animals (23). The bacterial cultures were serially diluted in BHI broth and plated onto BHI agar plates in order to determine the colony forming unit $(\mathrm{CFU}) / \mathrm{ml}$. The 
working cultures for experimental infection were adjusted to a final concentration of $1 \times 10^{9} \mathrm{CFU} / \mathrm{ml}$.

Female BALB/c mice (age, 4 weeks; weight, 13-14 g) were housed at $24 \pm 1^{\circ} \mathrm{C}$ and $60 \%$ relative humidity in a 12 -h light/dark cycle with access to food and water ad libitum. They were randomly divided into four groups (12 mice/group), and individual groups were injected intraperitoneally (i.p.) with $100 \mu \mathrm{l}$ of the ZY458 wild-type strain, ZD89 carrier strain, $458 \Delta$ vapE mutant strain or $458 \Delta$ vapE (pvapE) complemented strain cultures. The animals were monitored daily for 1 week for mortality and clinical signs, including depression, swollen eyes, ruffled hair, lethargy and nervous symptoms. Tissues of the heart, liver, spleen, lung and kidney from infected mice (12 mice/group) were harvested for detection of the SS2 bacteria by plating onto BHI agar plates. Positive cultures were confirmed by PCR using VapE-F and VapE-R primers (Table II).

Bacterial colonization assay. To evaluate the pathogenicity of SS2, the capacity of the bacteria to colonize the tissues of the heart, liver, spleen, lung and kidney of infected mice was analyzed using a colonization assay. Further BALB/c (13-14 g) mice were randomly divided into three groups (nine mice/group) and injected i.p. with $1 \times 10^{8} \mathrm{CFU} /$ mouse of one of the ZY458, ZD89 or 458 $\Delta$ vapE strains. One mouse from each group was euthanized by cervical dislocation at 12,24 and $36 \mathrm{~h}$ post-infection, and the tissues were collected and ground with an electric pestle (Tiangen Biotech Co., Ltd., Beijing, China) in $0.9 \% \mathrm{NaCl}(0.03 \mathrm{~g}$ tissue $/ \mathrm{ml})$. The supernatants were diluted 10 -fold and plated onto BHI agar plates. Following an overnight incubation, the bacterial colonies were counted and the data were expressed as $\mathrm{CFU} / \mathrm{g}$ of tissue, as described previously (24)

Distribution analysis of the vapE gene by PCR. The primers VapE-F and VapE-R were designed on the basis of the published sequence of the SS2 strain, 05ZYH33 (GenBank accession no. NC_009442), to detect the vapE gene from the genomic DNA of SS2 strains ZY458, SP3, SP6, 1330, ZD89, B22, B3 and SP8 by PCR. 16S rDNA served as the reference gene. Each reaction was conducted using a $25 \mu 1$ mixture containing $2.5 \mu \mathrm{l} 10 \mathrm{X}$ buffer, 25 pmol each primer, $2 \mathrm{mM}$ each deoxynucleoside triphosphate, 2.5 units Taq polymerase and $2.5 \mu 1$ supernatant of denatured bacteria. The PCR was performed with Techgene FTGENE2D thermocycler, under the following conditions: i) Initiation and elongation for $3 \mathrm{~min}$ at $94^{\circ}$; ii) 30 cycles of denaturation for $30 \mathrm{sec}$ at $94^{\circ}$, annealing for $30 \mathrm{sec}$ at $50^{\circ} \mathrm{C}$ and elongation for $2 \mathrm{~min}$ at $72^{\circ} \mathrm{C}$; and iii) a final elongation step at $72^{\circ} \mathrm{C}$ for $10 \mathrm{~min}$. Amplicons were visualized by running at $100 \mathrm{~V}$ for $30 \mathrm{~min}$ on a $1 \%$ agarose gel containing ethidium bromide (Takara Biotechnology Co., Ltd.). A DL2000 DNA ladder (Takara Biotechnology Co., Ltd.) was used as a size marker.

\section{Results}

Generation of vapE mutant. A vapE deletion mutant strain, $458 \Delta$ vapE, was generated by a homologous replacement method using ZY458 as the parent strain. The vapE gene knock-out mutant strain was confirmed by PCR (Fig. 1).

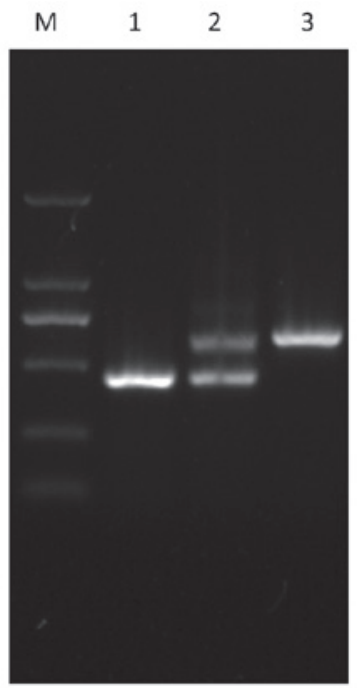

Figure 1. Identification of SS2 $458 \Delta$ vapE mutants and the complemented strain $458 \Delta$ vapE (pvapE) using a polymerase chain reaction assay. $M$ is the DL2000 DNA marker, and lanes 1 to 3 are PCR products amplified from SS2 strains 458 $\Delta v a p E, 458 \Delta v a p E$ (pvapE) and ZY458, respectively.

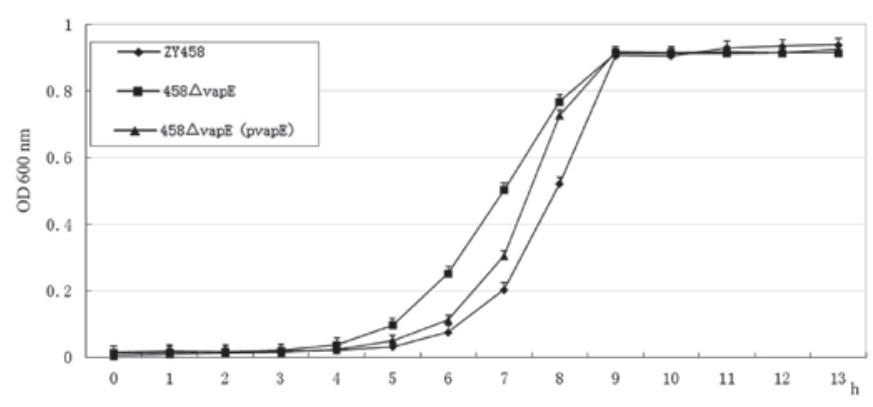

Figure 2. Growth curves of S. suis 2 wild-type strain ZY458 and its derivatives.

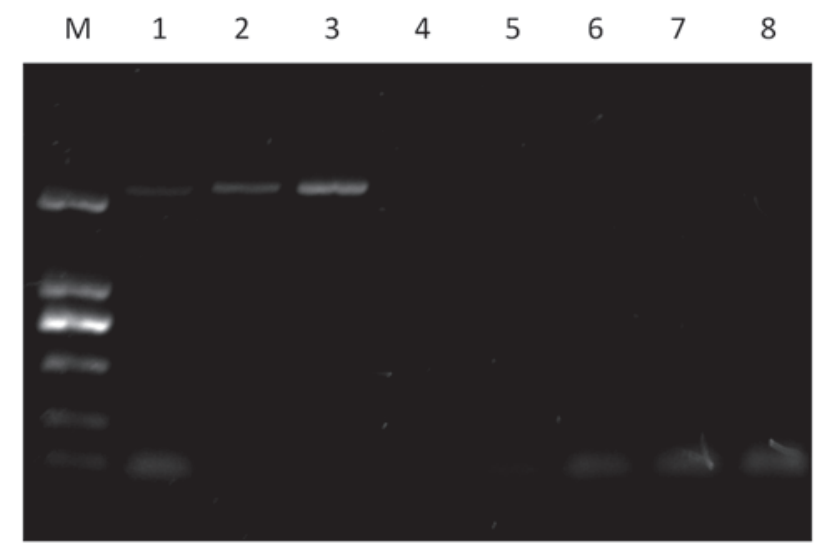

Figure 3. PCR detection of the vapE gene from virulent and avirulent strains of S. suis 2 identified in Table I. M is the DL2000 DNA marker (Takara). Lanes 1 to 8 are PCR products amplified from strains ZY458, SP3, SP6, 1330, ZD89, B22, B3 and SP8, respectively. The amplified vapE PCR fragment is 2292 bp. PCR, polymerase chain reaction.

Comparing the nucleotide sequences using basic local alignment search tool (BLAST) searching revealed that a 194 bp segment of the vapE gene (from 1 to $194 \mathrm{nt}$ of the 
Table III. Virulence of $S$. suis wild-type and mutant strains evaluated in BALB/c mice ${ }^{\mathrm{a}}$.

Percentage of mice from which SS2 was isolated

\begin{tabular}{|c|c|c|c|c|c|c|c|}
\hline \multirow[b]{2}{*}{ Strain } & \multirow[b]{2}{*}{ Morbidity (\%) } & \multirow[b]{2}{*}{ Mortality (\%) } & \\
\hline & & & Heart & Liver & Spleen & Lung & Kidney \\
\hline ZY458 & 100.0 & 100.0 & 100.0 & 100.0 & 100.0 & 100.0 & 100.0 \\
\hline$\Delta$ vapE & 100.0 & 0.0 & 0.0 & 0.0 & 0.0 & 0.0 & 0.0 \\
\hline$\Delta$ vapE (pvapE) & 100.0 & 83.3 & 83.3 & 83.3 & 83.3 & 83.3 & 83.3 \\
\hline Negative (ZD89) & 0.0 & 0.0 & 0.0 & 0.0 & 0.0 & 0.0 & 0.0 \\
\hline
\end{tabular}

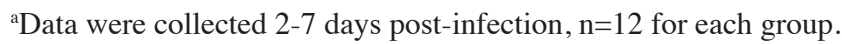

Table IV. Bacterial colonization of the tissues of mice infected with $S$. suis 2 (CFU/g tissue).

\begin{tabular}{|c|c|c|c|c|c|c|c|c|c|}
\hline \multirow[b]{2}{*}{ Organ } & \multicolumn{3}{|c|}{ ZY458 infection } & \multicolumn{3}{|c|}{$\Delta$ vapE infection } & \multicolumn{3}{|c|}{ ZD89 infection } \\
\hline & $12 \mathrm{~h}$ & $24 \mathrm{~h}$ & $36 \mathrm{~h}^{\mathrm{a}}$ & $12 \mathrm{~h}$ & $24 \mathrm{~h}$ & $36 \mathrm{~h}$ & $12 \mathrm{~h}$ & $24 \mathrm{~h}^{\mathrm{b}}$ & $36 \mathrm{~h}^{\mathrm{b}}$ \\
\hline Heart & $6.6 \times 10^{10}$ & $2.0 \times 10^{8}$ & $(-)$ & $1.3 \times 10^{10}$ & $2.0 \times 10^{7}$ & $5.0 \times 10^{5}$ & $1.5 \times 10^{6}$ & $(-)$ & $(-)$ \\
\hline Liver & $8.7 \times 10^{10}$ & $1.3 \times 10^{9}$ & $(-)$ & $3.0 \times 10^{10}$ & $2.4 \times 10^{8}$ & $5.5 \times 10^{6}$ & $2.0 \times 10^{6}$ & $(-)$ & $(-)$ \\
\hline Spleen & $2.8 \times 10^{11}$ & $1.3 \times 10^{9}$ & $(-)$ & $2.8 \times 10^{10}$ & $5.5 \times 10^{8}$ & $1.2 \times 10^{6}$ & $3.0 \times 10^{6}$ & $(-)$ & $(-)$ \\
\hline Lung & $1.1 \times 10^{10}$ & $6.0 \times 10^{8}$ & $(-)$ & $2.4 \times 10^{10}$ & $4.2 \times 10^{7}$ & $5.5 \times 10^{5}$ & $7.0 \times 10^{6}$ & $(-)$ & $(-)$ \\
\hline Kidney & $8.7 \times 10^{10}$ & $1.5 \times 10^{8}$ & $(-)$ & $1.7 \times 10^{10}$ & $4.7 \times 10^{7}$ & $2.5 \times 10^{5}$ & $4.0 \times 10^{6}$ & $(-)$ & $(-)$ \\
\hline
\end{tabular}

${ }^{\mathrm{a}} \mathrm{All}$ the animals were deceased at this time point. ${ }^{\mathrm{b}}$ No bacteria detected.

vapE coding sequence) had been deleted without alteration of the remaining sequence.

Generation of a functional complemented $\Delta v a p E$ mutant. The PCR-amplified structural gene of vapE was cloned into a pAT18 shuttle vector. The resultant plasmid was confirmed by PCR (Fig. 1) and designated as pAT18::vapE, which was then electrotransfected into $458 \Delta \mathrm{vapE}$ cells to produce

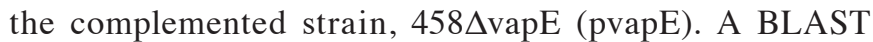
analysis of the nucleotide sequences in the National Center for Biotechnology Information database with the vapE gene confirmed that the amplified 2,292 bp fragment was identical with the other strains.

Bacterial growth rates. To determine whether the deletion of the vapE gene leads to a defect in bacterial growth, the growth characteristics of wild-type SS2 strain ZY458, the vapE deletion mutant, 458 $\Delta \mathrm{vapE}$, and the complemented strain, $458 \Delta$ vapE (pvapE), were compared at $37^{\circ} \mathrm{C}$ in BHI broth. The optical density values of the bacterial cultures at $600 \mathrm{~nm}$ were measured. The growth curves indicated that the growth rates of the mutant strains $458 \Delta \mathrm{vapE}$ and $458 \Delta \mathrm{vapE}$ (pvapE) were similar to that of the wild-type strain, ZY458 (Fig. 2).

The virulence of the $\Delta v a p E$ mutant is attenuated in mice. To further assess the effect of vapE deletion on the pathogenesis of SS2, four groups of mice were infected with one of the SS2 wild-type strain ZY458, the carrier strain, ZD89, or the mutant strains, $458 \Delta \mathrm{vapE}$ or $458 \Delta \mathrm{vapE}$ (pvapE). The results indicated that all mice infected with wild-type SS2 exhibited severe clinical symptoms, including depression, apathy, fever, anorexia, emaciation, swollen eyes and neural disorders, and died within 2 days of infection (Table III). Similarly, animals infected with the complemented strain $458 \Delta$ vapE(pvapE) developed severe clinical symptoms and $83.3 \%$ of the mice died 2 days post-infection. By contrast, $100 \%$ of the mice infected with mutant strain $458 \Delta$ vapE exhibited only mild clinical symptoms in the first 2 days post-infection, and recovered fully within a week. None of the mice injected with ZD89 developed any clinical symptoms. Furthermore, SS2 bacteria were recovered from the organs of mice infected with ZY458 and 458 $\Delta$ vapE (pvapE). However, no bacteria were detected in the heart, liver, spleen, lung or kidney of any mice infected with $458 \Delta \mathrm{vapE}$ or ZD89 over a test period of 7 days post-infection (data not shown).

To further evaluate the virulence attenuation of $458 \Delta \mathrm{vapE}$, a bacterial colonization assay was performed. As indicated in Table IV, a reduction in clone-forming efficiency was observed in the infected mice. Mice infected with ZY458 died within $36 \mathrm{~h}$, in contrast, mice infected with $458 \Delta$ vapE remained alive with $10^{5}-10^{6} \mathrm{CFU} / \mathrm{g}$ of tissue.

Distribution analysis of the vapE gene in various $S$. suis 2 strains. To determine whether the vapE gene exists only in virulent strains of SS2, PCR amplification of the vapE gene was performed using primers of VapE-F and VapE-R (Table II). A 2,292 bp portion of the target fragment was amplified from the virulent strains (ZY458, SP3, SP6), but not from any of the avirulent (1330) and carrier strains that were investigated (ZD89, B22, B3 and SP8) (Fig. 3). 


\section{Discussion}

S. suis 2 is a major swine pathogen and a zoonotic agent that leads to septicemia and meningitis in pigs and humans (25). An improved understanding of its pathogenesis is critical for developing effective approaches to combat its severe infectivity. A 1,533 bp vapE open reading frame sequence of the ZY458 virulent strain was submitted to GenBank (accession no. JX270678). There was a 100\% identity match to the corresponding sequences of $S$. suis P1/7 SSU1332 (GenBank accession no. AM946016), S. suis A7 SSUA7_1349 (accession no. CP002570), S. suis GZ1SSGZ1_1350 (accession no. CP000837), S. suis BM407 SSUBM407_1409 (accession no. FM252032), S. suis SC84 SSUSC84_1362 (accession no. FM252031), S. suis 98HAH33 SSU98_1525 (accession no. CP000408), S. suis 05ZYH33 SSU05_1514 (accession no. CP000407), and serotype 1/2 S. suis SS12 SSU12_1401 (accession no. CP002640), serotype 14 S. suis JS14 SSUJS14_1484 (accession no. CP002465).

To investigate the role of the vapE gene in the pathogenesis of SS2, a vapE in-frame deletion mutant of wild-type strain ZY458 was generated using a gene knock-out, and the impact of the vapE deletion on the virulence of $S$. suis 2 was assessed in a mouse infection model. The current findings indicated that mice infected with the ZY458 wild-type strain or the $458 \Delta \mathrm{vapE}$ (pvapE) complemented strain presented severe clinical symptoms, including body weight loss, and died within 2 days of infection, suggesting that the complemented strain retained the virulence of the wild-type strain. By contrast, mice inoculated with the vapE deletion mutant developed only mild clinical signs, with marginal weight loss in the first 2 days post-infection, and they recovered fully within a week. This indicates that deletion of the vapE gene in the ZY458 virulent strain leads to reduced pathogenicity of SS2 in mice. Together with the molecular evidence that the vapE gene is present only in virulent SS2 strains, these findings suggest that the vapE gene is critical for the pathogenicity of S. suis 2 .

The exact function of the vapE gene in SS2 remains unclear; however, the vapE protein was predicted to be cytoplasmic by the Cell-Ploc package (26). The corresponding gene products in S. suis strains P1/7, BM407 and SC84 have been annotated as 'putative phage primase' in GenBank, and as 'virulence-associated protein E' in other S. suis strains. In a previous study, Wei et al (27) identified various putative PAIs of $S$. suis 2, with the vapE gene located in PAI4. Notably, this putative PAI only existed in virulent $S$. suis 2 strains and was able to encode phage integrases, certain hypothetical proteins, phage protein and tRNA. On the basis of its original phage elements, vapE has been suggested to be from a bacteriophage that integrated into the $S$. suis 2 genome through a horizontal gene transfer (28). Its absence may reduce the expression of other virulence-associated proteins in PAI4, thus reducing the overall pathogenicity of $S$. suis 2 . As a result, animals exhibited mild clinical symptoms and recovered fully after 2 days.

In conclusion, the results reported in the present study clearly indicate that $v a p E$ is associated with the pathogenicity of S. suis 2. Although its function requires further investigation, this finding may contribute to the understanding of the pathogenesis of S. suis 2 and may help in the development of novel strategies against $S$. suis infections. Further investigation will require research into the transcriptome of $S$. suis ZY458 and $458 \Delta$ vapE.

\section{Acknowledgements}

We would like to thank Dr JF Fernández-Garayzábal (Departamento Patología Animal I, Facultad de Veterinaria, Universidad Complutense, Spain) and Dr Marcelo Gottschalk (University of Montreal, Faculty of Veterinary Medicine, St. Hyacinthe, QC, Canada) for kindly providing S. suis 2 strains and $S$. suis 2 avirulent reference strain 1330, respectively. The present study was supported by grants from National Natural Science Foundation of China (grant nos. 31172340 and 31101790/C1803).

\section{References}

1. Wertheim HF, Nghia HDT, Taylor W and Schultsz C: Streptococcus suis: an emerging human pathogen. Clin Infect Dis 48: 617-625, 2009.

2. Yu H, Jing H, Chen Z, Zheng H, Zhu X, Wang H, Wang S, Liu L, Zu R, Luo L, et al; Streptococcus suis study groups: Human Streptococcus suis outbreak, Sichuan, China. Emerg Infect Dis 12: 914-920, 2006.

3. Gottschalk M and Segura M: The pathogenesis of the meningitis caused by Streptococcus suis: the unresolved questions. Vet Microbiol 76: 259-272, 2000.

4. Fittipaldi N, Segura M, Grenier D and Gottschalk M: Virulence factors involved in the pathogenesis of the infection caused by the swine pathogen and zoonotic agent Streptococcus suis. Future Microbiol 7: 259-279, 2012.

5. de Greeff A, Buys H, Verhaar R, Dijkstra J, van Alphen L and Smith $\mathrm{HE}$ : Contribution of fibronectin-binding protein to pathogenesis of Streptococcus suis serotype 2. Infect Immun 70: 1319-1325, 2002.

6. Baums CG, Kaim U, Fulde M, Ramachandran G, Goethe R and Valentin-Weigand P: Identification of a novel virulence determinant with serum opacification activity in Streptococcus suis. Infect Immun 74: 6154-6162, 2006.

7. Fittipaldi N, Sekizaki T, Takamatsu D, de la Cruz Domínguez-Punaro M, Harel J, Bui NK, Vollmer W and Gottschalk M: Significant contribution of the pgdA gene to the virulence of Streptococcus suis. Mol Microbiol 70: 1120-1135, 2008

8. Si Y, Yuan F, Chang H, Liu X, Li H, Cai K, Xu Z, Huang Q, Bei W and Chen H: Contribution of glutamine synthetase to the virulence of Streptococcus suis serotype 2. Vet Microbiol 139: 80-88, 2009.

9. Ge J, Feng Y, Ji H, Zhang H, Zheng F, Wang C, Yin Z, Pan X and Tang J: Inactivation of dipeptidyl peptidase IV attenuates the virulence of Streptococcus suis serotype 2 that causes streptococcal toxic shock syndrome. Curr Microbiol 59: 248-255, 2009.

10. Zhang XH, He KW, Duan ZT, Zhou JM, Yu ZY, Ni YX and Lu CP: Identification and characterization of inosine 5-monophosphate dehydrogenase in Streptococcus suis type 2. Microb Pathog 47: 267-273, 2009.

11. Wu T, Zhao Z, Zhang L, Ma H, Lu K, Ren W, Liu Z, Chang H, Bei W, Qiu Y and Chen H: Trigger factor of Streptococcus suis is involved in stress tolerance and virulence. Microb Pathog 51: 69-76, 2011

12. Li P, Liu J, Zhu L, Qi C, Bei W, Cai X, Sun Y and Feng S: VirA: A virulence-related gene of Streptococcus suis serotype 2. Microb Pathog 49: 305-310, 2010.

13. Zheng F, Ji H, Cao M, Wang C, Feng Y, Li M, Pan X, Wang J, Qin Y, Hu F and Tang J: Contribution of the Rgg transcription regulator to metabolism and virulence of Streptococcus suis serotype 2. Infect Immun 79: 1319-1328, 2011.

14. Bonifait L and Grenier D: The SspA subtilisin-like protease of Streptococcus suis triggers a pro-inflammatory response in macrophages through a non-proteolytic mechanism. BMC Microbiol 11: 47, 2011

15. Willenborg J, Fulde M, de Greeff A, Rohde M, Smith HE, Valentin-Weigand $\mathrm{P}$ and Goethe R: Role of glucose and CcpA in capsule expression and virulence of Streptococcus suis. Microbiology 157: 1823-1833, 2011. 
16. Tang $\mathrm{Y}$, Zhang $\mathrm{X}, \mathrm{Wu} \mathrm{W}, \mathrm{Lu} \mathrm{Z}$ and Fang W: Inactivation of the sodA gene of Streptococcus suis type 2 encoding superoxide dismutase leads to reduced virulence to mice. Vet Microbiol 158 360-366, 2012.

17. Chen C, Tang J, Dong W, Wang C, Feng Y, Wang J, Zheng F, Pan X, Liu D, Li M, et al: A glimpse of streptococcal toxic shock syndrome from comparative genomics of $S$. suis 2 Chinese isolates. PLoS One 2: e315, 2007.

18. Li M, Wang C, Feng Y, Pan X, Cheng G, Wang J, Ge J, Zheng F, Cao M, Dong Y, et al: SalK/SalR, a two-component signal transduction system, is essential for full virulence of highly invasive Streptococcus suis serotype 2. PLoS One 3: e2080, 2008.

19. Qi C, Liu J, Zhu LW, Wang WD, Meng FQ and Feng SZ: Genetic difference between Streptococcus suis serotype 2 virulent strain and avirulent strain by suppression subtractive hybridization. Chin J Vet Sci: 588-593, 2009 (In Chinese).

20. Sambrook J and Russell DW: Molecular Cloning: A Laboratory Manual, 3rd edition. Cold Spring Harbor Laboratory Press, New York, 2001.

21. Takamatsu D, Osaki M and Sekizaki T: Construction and characterization of Streptococcus suis-Escherichia coli shuttle cloning vectors. Plasmid 45: 101-113, 2001.

22. Takamatsu D, Osaki M and Sekizaki T: Thermosensitive suicide vectors for gene replacement in Streptococcus suis. Plasmid 46 140-148, 2001.

23. [No Authors Listed]: CIOMS International guiding principles for biomedical research involving animals. Altern Lab Anim 12: ii- 1985.
24. Wang G, Lo LF and Maier RJ: The RecRO pathway of DNA recombinational repair in Helicobacter pylori and its role in bacterial survival in the host. DNA Repair (Amst) 10: 373-379, 2011.

25. Gottschalk M, Segura M and Xu J: Streptococcus suis infections in humans: The Chinese experience and the situation in North America. Anim Health Res Rev 8: 29-45, 2007.

26. Chou KC and Shen HB: Cell-PLoc: A package of web servers for predicting subcellular localization of proteins in various organisms. Nature Protoc 3: 153-162, 2008.

27. Wei W, Ding GH, Wang XQ, Sun JC, Tu K, Hao P, Wang C, Cao ZW, Shi TL and Li YX: Comparative genome analysis of Streptococcus suis. Chin Sci Bull 51: 808-818, 2006.

28. Juhas M, van der Meer JR, Gaillard M, Harding RM, Hood DW and Crook DW: Genomic islands: Tools of bacterial horizontal gene transfer and evolution. FEMS Microbiol Rev 33: 376-393, 2009.

29. Trieu-Cuot P, Carlier C, Poyart-Salmeron C and Courvalin P: Shuttle vectors containing a multiple cloning site and a lacZ $\alpha$ gene for conjugal transfer of DNA from Escherichia coli to gram-positive bacteria. Gene 102: 99-104, 1991.

30. Quessy S, Dubreuil JD, Caya M and Higgins R: Discrimination of virulent and avirulent Streptococcus suis capsular type 2 isolates from different geographical origins. Infect Immun 63: 1975-1979, 1995

31. Vela AI, Goyache J, Tarradas C, Luque I, Mateos A, Moreno MA, Borge C, Perea JA, Domínguez L and Fernández-Garayzábal JF: Analysis of genetic diversity of Streptococcus suis clinical isolates from pigs in Spain by pulsed-field gel electrophoresis. J Clin Microbiol 41: 2498-2502, 2003. 